\title{
Livestock system as a mitigation measure of a wind farm in a mountain area
}

\author{
Antoniotto Guidobono Cavalchini, Gabriele Daglio, Massimo Lazzari, Stefania Leonardi \\ Department of Health, Animal Science and Food Safety, Università degli Studi di Milano
}

\begin{abstract}
The study concerns a mountain territory, bordering Liguria, Piemonte, Lombardia and Emilia, where a high power $151 \mathrm{MW}$ wind farm, with 42 tower of 3.6 MW power, has been proposed. As a measure of environmental mitigation, the realization of a livestock system of a herd of sucker cows pasturing in the wind farm areas is proposed. This has implications for environmental maintenance, employment in a territory gradually losing its population, and for tourism. The study, having focused on those aspects that reduce landscape impact and carrying out an analysis of the individual areas to evaluate forage resources and the different pastoral indexes, identifies the maximum sustainable load of animals ( $335 \mathrm{UBA} / \mathrm{ha}$ ) in the current conditions of neglect. So, some measures to improve and increase sustainable herds have been proposed and examined. The operations include: stone removal; light harrowing; overseeding; creation of fodder reserves for periods of shortage; and grazing will be managed by taking turns. Based on the results of two other studies, both previous tests carried out on site, encourage us to think that we will be able to increase the maximum sustainable seasonal load for the current situation by more than $50 \%$. This means a herd of 500 UBA equal to a gross PLV, for the grazing period of 180 days, of $€ 400,000$ and so guarantee an adequate income to 3-4 UL (labor unit), and of $€ 650,000 / y e a r$ in case the chain is completed during the winter months in structures located in the valley. In this case, the PLV obtained could assure income to 6-7 employees, which would be extremely important for the socio-economic conditions of the valley; in consideration of the induced activities- meat processing, marketing and tourism facilities- which could be made available. Experimental tests of the technical improvements described will be carried out in the next season.
\end{abstract}

Correspondence: Antoniotto Guidobono Cavalchini, Department of Health, Animal Science and Food Safety, Università degli Studi di Milano, Via Celoria 10, 20133, Milano, Italy.

E-mail: antoniotto.cavalchini@unimi.it

Key words: wind farm; livestock system, mitigation measure, mountain area,

(C) Copyright A. Guidobono Cavalchini et al., 2013

Licensee PAGEPress, Italy

Journal of Agricultural Engineering 2013; XLIV(s2):e99

doi:10.4081/jae.2013.s2.e9g

This article is distributed under the terms of the Creative Commons Attribution Noncommercial License (by-nc 3.0) which permits any noncommercial use, distribution, and reproduction in any medium, provided the original author(s) and source are credited.

\section{Introduction}

The area studied includes the Giarolo, Roncassi and Ebro mountain crests bordering on Liguria, Piemonte, Lombardia and Emilia, also called of "the Quattro Regioni". The territories are going through a period of severe depopulation causing an almost deanthropic state. Consequently also the agro-zootecnical activities have dropped in the past years (Figure 1). Among the major causes are: the lack of productive job alternatives to replace the agricultural ones after the war during which in Italy industry replaced agriculture; shortage of efficient infrastructures to link the urban/industrial centers, and, above all an impervious territory with few resources.

Yet, one of the resources is the wind. Until recently it was considered a nuisance, but today it has regained its importance also in economic terms. Anemologic studies carried out on crests revealed that median annual speed is higher than $5 \mathrm{~m} / \mathrm{s}$ with peaks above $6 \mathrm{~m} / \mathrm{s}$ in the winter months, with an annual production of $2800 \mathrm{kWh} / \mathrm{kW}$ installed power (Figure 2). This is why in these last few years many wind farm proposals have been put forward; our studies concern the installation of 42 wind generators, 3.6 MW nominal power, totaling 151,2 MW (Figure 3).

Obviously such an intervention is harmful, having a permanent environmental impact, especially on the landscape, which should not to be taken lightly. The repercussions for the expected economic gains (7-9\% of revenues from energy produced) are significant for the area. The study proposes the environmental mitigation measures to be taken; improvement and realization of pasture-land resources and a cow calf animal husbandry system. It's an interesting paradox, the solution to the negative technological impact could well be found in traditional measures.

Pastures: the crests studied were once a precious resource, but they have been progressively neglected. Up to the 50s the pastures, besides being used for grazeland, they were cut to create a fodder reserve and were mostly commonly managed. Instead today, while the local population has almost completely given up the use of the pastures, due to the lack of livestock; the grazeland is utilized by lowland livestock breeders for summer grazing thanks to regional incentives. It is obviously a non-solution with little attention paid to the needs of the territory.

\section{Materials and methods}

The fodder resource studied was assessed by locating plant species via satellite image photo-interpretation using a GSI. The areas located were thus divided into virtual polygons of which the area was calculated. Through video observation each polygon was assigned a "Su" parameter which expresses the percentage of grazeland surface and its Valore Pastorale (VP) (Pasture Value). The polygons were given a conversion coefficient $\mathrm{K}$ for $\mathrm{VP}$ and a fragility coefficient $\mathrm{CF}$, according to a proven method (Cavallero et al., 2002; 2007). 
Thus applying to each polygon the formula $\mathrm{CMMU}=\mathrm{VP} * \mathrm{~K}^{*} \mathrm{~S}_{\mathrm{u}}{ }^{*} \mathrm{CF}$ for each one we can determine Carico Massimo Mantenibile Unitario (CMMU) (Unitary Maintainable Maximum Load), expressed in [UBA * $\mathrm{ha}^{-1 *}$ anno $^{-1}$ (UBA= Adult Bovine Unit)]. By multiplying the Unitary Maintainable Maximum Load by the area of the polygon and the period of summer pasture (180 days), subsequently we referred to the Carico Massimo Mantenibile Stagionale (Maintainable Maximum Seasonal Load) referred to the pastureland expressed in [UBA/area,season]. So the Reduction "Kr" coefficient was introduced, which, according to species and breed, (Cavallero et al., 2007), allows the calculation of the Suggested Maintainable Load for the whole area expressed in [UBA/area,season].

Finally, by applying the formula: $\mathrm{VP}=\Sigma\left(\mathrm{CS}_{\mathrm{i}}{ }^{*} \mathrm{I}_{\mathrm{Si}}\right) * 0,2$, (Daget \& Poissonet, 1969; 1971), by determining plant composition we were able to calculate Pasture Value. The Pasture Values used were taken from a previous study in the same area (Giordano and Terzolo 2001), after verifying, by chance, some values.

\section{Results}

From the studies carried out using the methods described above, the results are as follows:
The sum of the areas of the individual polygons digitized gives a comprehensive value of $626 \mathrm{Ha}$. However, for various reasons, (e.g. excessive steepness, low pasture value, roads, high number of not edible species, etc.), use of the pastures is limited. Only 444 ha. can be used for pasture. Pasture values VP and Carico Massimo Mantenibile Unitario (CMMU) (Unitary Maintainable Maximum Load), calculated with the method above, are broken down for the single areas in Figure 4.

In conclusion the following values were obtained:

- Unitary Maintainable Maximum Load: 0,309 [UBA/ha, year]; average value referred to the whole area;

- Maintainable Maximum Seasonal Load: 447 [UBA /area ,summer pasture period]; total value referred to the whole area studied;

- Suggested Maintainable Load: 335 [UBA /area ,summer pasture period]; total value referred to the whole area studied.

Following the analysis of the fodder resources agro-zootecnical interventions are proposed to improve productivity and efficiency in the area. The interventions include stone removal in some pasture areas and light harrowing the area to remove agricultural residues of the previous season. In addition, in low value areas $(\mathrm{VP}<25)$, were the use of machines is possible, overseeding has been taken into consideration. To manage the area by turns, some infrastructural investments for electric fences, water troughs and feed supplements are required. For the latter, hay is used as part of the turn-taking plan, using rotobalers or STack Hand. In both cases rain resistant hay
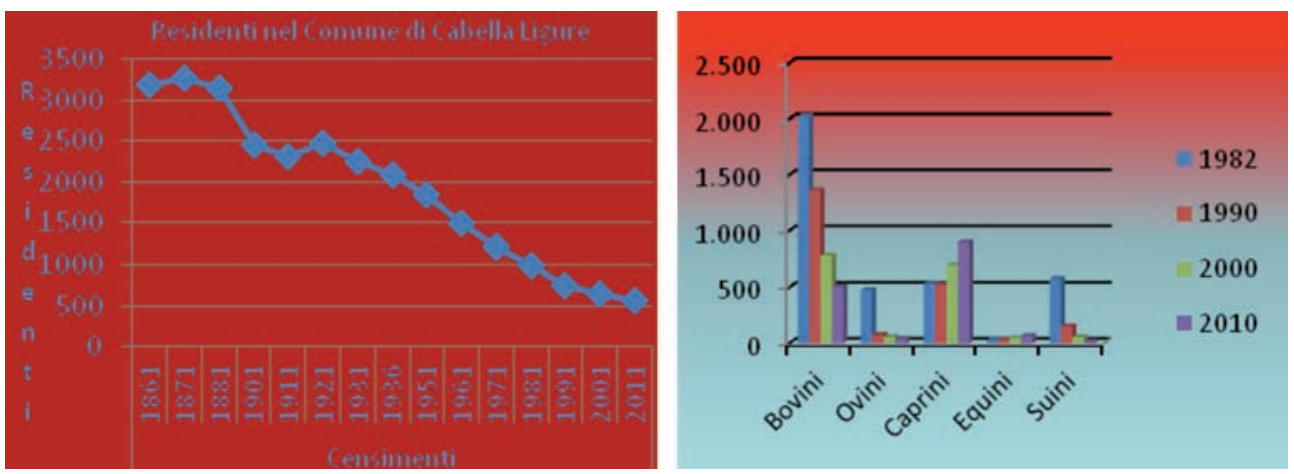

Figure 1. State of the population (Cabella Ligure) and the zootecnical patrimony.

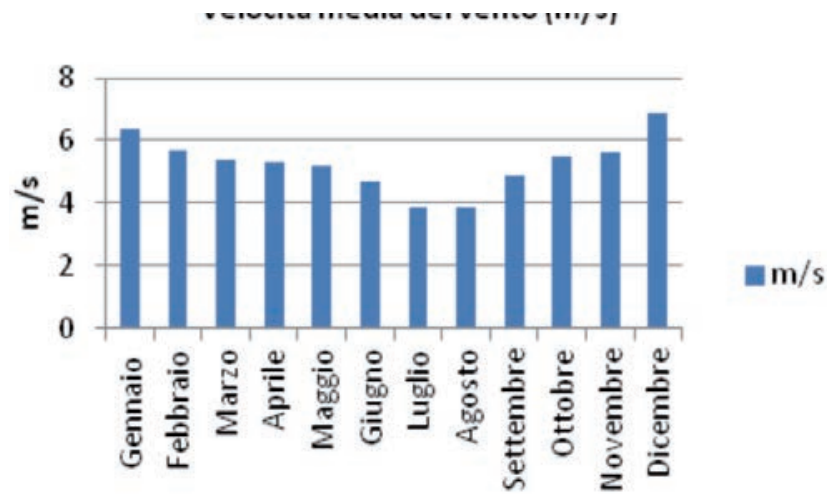

Figure 2. Wind average monthly speed.

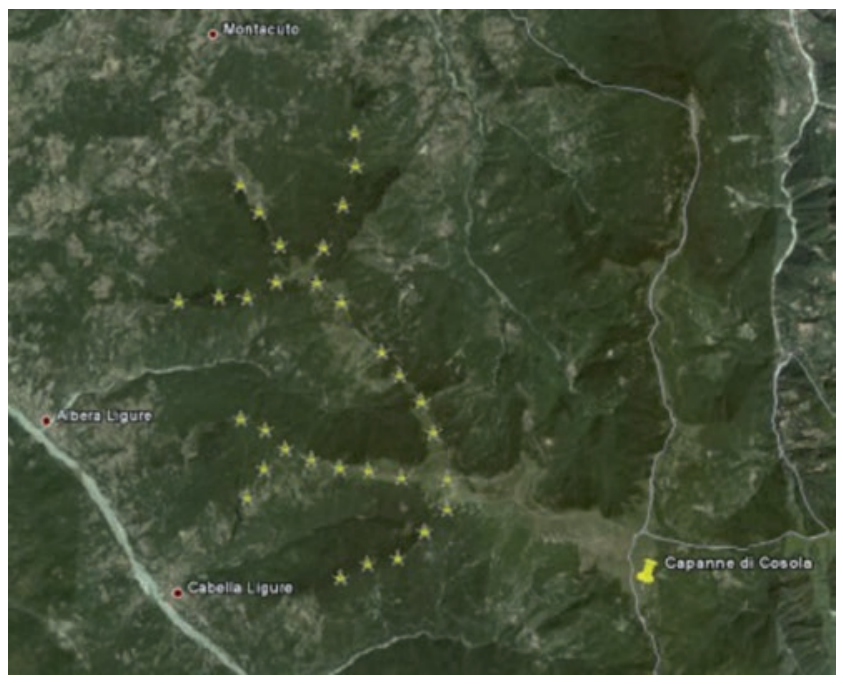

Figure 3. Wind generators position. 

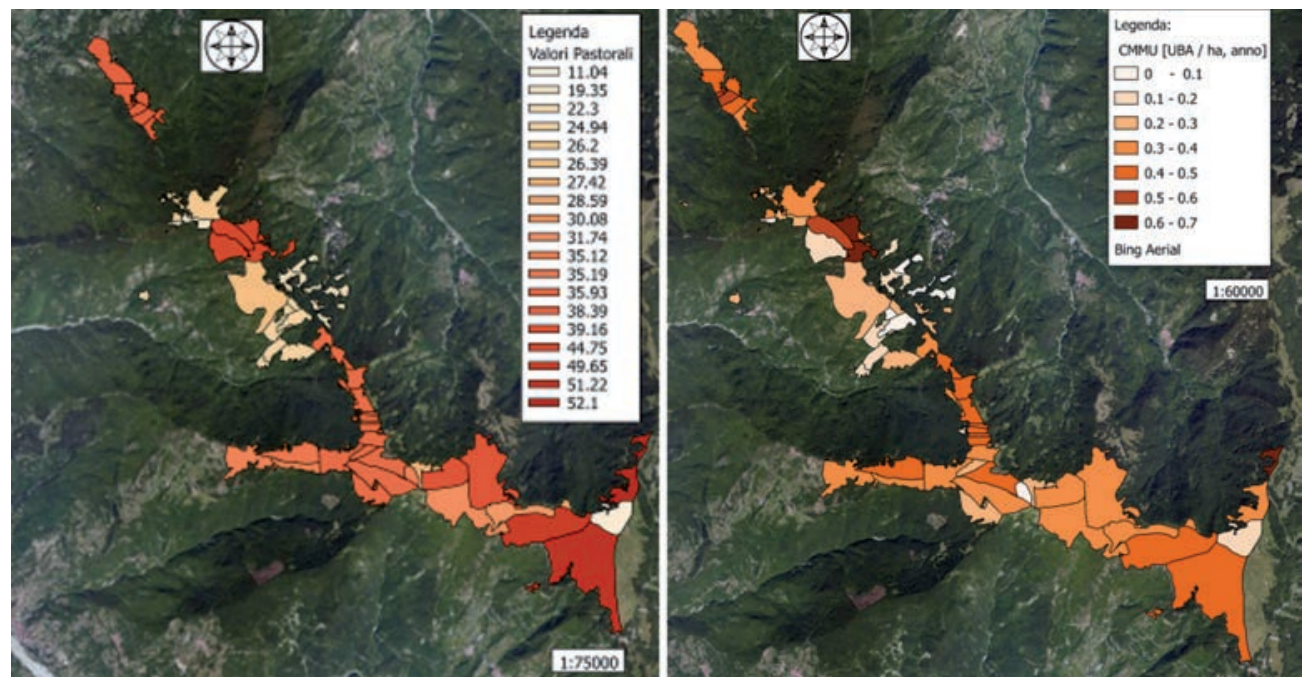

Figure 4. Pasture Values (left) and Unitary Maintainable Maximum Load (right) of the area.

stacks easily accessible to the animals would be made available.

From satellite video analysis stone removal would include a 50 ha area, mostly involving the towns of Cantalupo and Montacuto. Slopes above a $60 \%$ inclination would be excluded; light harrowing would be used in a 310 ha area. After a preliminary analysis it was decide that overseeding take place in an area of 30-40 ha/year, in order to assess the benefits and pick out the most productive and suitable species. The areas to be used as fodder reserves, singled out for its productivity, soil morphology and turn-taking plan with reference to the pasture, is 40 ha.

Based on various experiments carried out in the didactic-experimental farm of Borgo Adorno of the University of Milan bordering the areas studied, it was estimated that the proposed improvement interventions, coupled with the turn-taking plan, a Suggested Maintainable Load value near 500 [UBA/area is obtained, in the period of summer pasture period.

\section{Conclusions}

The studies clearly show that territorial deterioration and of abandonment will continue unless radical changes take place. A wind farm would be an opportunity for forecasted economic returns if they are shrewdly reinvested on the territory. However, the impact on the landscape and modest employment opportunities are not to be overlooked. The proposed measures concentrating on the primary system by the improvement of a natural resource, the pasture, environmentally valu- able, could mitigate the negative impact of a large wind farm. In this way, two different types of businesses could coexist and integrate: the first, of an industrial nature, for the production of renewable energy; the second for the production of quality foods, characterized by a common denominator: the use of natural resources.

As far as employment is concerned, the prime objective of each action on the territory such as the one examined, the zootecnical system proposed, 500 nursing cows, justifies 2-3 Work Units and as such insignificant, but it starts up a PLV of $€ 400,000$ not negligible since it is obtained with modest technical means, negligible in terms of economics. To keep in mind also the start of induced consumption with businesses (tourism, meat production, distribution, direct consumption in the local restaurants, etc.) interesting for a valley-based socioeconomy in sharp recession.

\section{References}

Cavallero et altri. I tipi pastorali delle Alpi Piemontesi., Albero Perdisa editore., Bologna., 2007.

Cavallero A., Rivoira G., Talamucci P., Pascoli. In Baldoni R. \& Giardini L. Coltivazione erbacee. Patron editore., Bologna 2002.

Daget P. \& Possonet J.: Analyse Phytologique des pairies. Document 48, Centre National de la Re Recherche B.P. Montpellier 1969.

Daget P. \& Possonet J.,: Une métode d' analyse phytologique des praires. Annales Agronomiques 1971. 